\title{
Processing Possibilities of Birch Outer Bark into Green Bio-composites
}

\author{
Aigars Paze, Janis Rizhikovs, Prans Brazdausks, Maris Puke, Juris Grinins, \\ Ramunas Tupciauskas, Ance Plavniece \\ Latvian State Institute of Wood Chemistry, 27 Dzerbenes street, Riga, LV-1004, Latvia
}

\begin{abstract}
The main objective of the study was to obtain bio-composites from grey alder sawdust using a mixture of birch outer bark suberinic acids as a binder, and to test their mechanical properties. Ethanol-extracted birch outer bark was used as a raw material for the investigation. Characteristics (suberinic acids content, epoxy acids content and acid number) of the hydrolytically depolymerized birch outer bark binder were also determined. The initial filler/binder ratio and molding parameters (temperature and pressure) were established by the full factorial design. Preliminary data showed that the increase of the pressing temperature from 160 to $200{ }^{\circ} \mathrm{C}$ at a pressure of $3.5 \mathrm{MPa}$ resulted in a minor growth of the boards' density (up to $1.0 \mathrm{~g} / \mathrm{cm}^{3}$ ) and bending strength (up to $17.1 \mathrm{MPa}$ ).

Our investigation has shown that it is possible to use one of the plywood production residues - outer birch bark - as a raw material for obtaining particleboards, which have mechanical properties beyond the standard limits. The used method is also environmentally friendly, easy realizable in practice and has a potential to be cost-effective.
\end{abstract}

Keywords: Bio-composites, birch outer bark, suberinic acids.

\section{INTRODUCTION}

Processing of birch bark has a high potential in both Latvia and Europe. Besides the veneer industry, there are other important industries, such as the furniture or cellulose industry in Europe, which has a large amount of residual birch bark combusted for energy needs. Therefore, an industrial research was started to develop the knowledge basis and gain a better understanding of the possibilities of birch bark processing in the scope of circular bio-economy.

A common method for producing composites is to use synthetic thermo-reactive binders: phenolformaldehyde, carbamide-formaldehyde or isocyanide based resins. These composite materials are toxic to humans during the production and exploitation of the products because of the formaldehyde emission. If the concentration of formaldehyde is above $0.1 \mathrm{ppm}$ in the air, it begins to irritate the eyes, throat and nasal mucosa, as well as to cause difficulty in breathing. In 2004, the International Agency for Research on Cancer of the World Health Organization found formaldehyde to be a carcinogenic compound [1].

To reduce formaldehyde emissions, adhesive additives such as boric acid or calcium metasilicate can be used, but it solves the problem only partially (emission reductions of 15-30 \%) [2]. From synthetic binders, less toxic and without harmful emissions are isocyanate-based adhesives. However, these binders are significantly more expensive than phenolformaldehyde and urea-formaldehyde binders.
From natural products, plant protein-based adhesives are widely used as binders. However, there is a problem that the moisture resistance of such particleboards is low [3]. It is well described in the scientific literature that many natural binders have a common drawback - food products such as soy flour or starch are used as the main component. In some cases, toxic and carcinogenic $\alpha$-epichlorohydrin is used, for example, to improve the water resistance of soy protein-based adhesives [4].

Silver birch (Betula pendula Roth.) is widely used in the Latvian plywood industry, whose one of the processing by-products - birch outer bark - has a high content of valuable extractives (up to $35 \%$ from oven dry (o.d.) birch outer bark). These extractives have a very wide range of different types of applications (pharmacy, cosmetology etc.); therefore, there is a high commercialization potential. It can be expected that, in the near future, the production capacity of such extractives will increase significantly [5]. Thus, the amount of birch outer bark extraction residues will also increase, which could be efficiently processed into a green binder for production of wood particle bio-composites.

A beneficial, accessible and ecological binder produced from birch outer bark is hydrophobic suberin. It consists of 40-45\% from o.d. birch outer bark and is usually isolated as suberinic acids or partly depolymerized suberin [6], [7]. Russian scientists have already tried to obtain bio-composites, as a binder using isolated suberinic acids of birch outer bark [8]. However, at the Latvian State Institute 
of Wood Chemistry, a relatively simpler and hence more efficient method for processing of extracted birch outer bark into a particleboard binder has been invented and patented. Following this methodology, a mixture of birch outer bark suberinic acids and a complex of insoluble bark processing residue is obtained together as a binder, which is mixed with the filler (wood particles), and bio-composites are prepared by hot pressing [9].

Grey alder used to be a less desirable raw material because of its low quality; as a result, its utilization was mainly limited to household heating and lowvalue products, such as packaging and pallets. Today, the situation has changed, and sufficient amounts of high-quality grey alder lumber as well as processing by-products - sawdust - are available in the market. Therefore, the main objective of the study was to obtain medium density bio-composites from grey alder (Alnus incana (L.) Moench) sawdust using a mixture of birch outer bark suberinic acids and a complex of insoluble bark processing residue as a binder, and to test their mechanical properties.

\section{MATERIALS AND METHODS \\ A. Preparation of Feedstock}

The birch bark (Betula pendula Roth.) from a plywood factory in Latvia was used as a feedstock to obtain a binder. At first, the collected birch bark was dried at room temperature to 7-10\% moisture content and then ground to chips by a hummer cutting mill (Retsch SM 100) to pass a $2.0 \mathrm{~mm}$ sieve. The outer bark was separated from the inner bark by the floating method, wherein milled birch bark was soaked by mixing from time to time in deionized water for $24 \mathrm{~h}$. Finally, outer bark (the floating part of the mixture) was collected and dried to 2-4\% moisture content in a convection-type oven at $50{ }^{\circ} \mathrm{C}$. Bark

B. Chemical Composition Analysis of Birch Outer

Extractives of birch outer bark were analyzed by a Soxhlet extraction apparatus. Samples (size of particles 0.4-2.0 mm) were extracted with ethanol (95 $\% \mathrm{v} / \mathrm{v}$ ) for $11 \mathrm{~h}$ to be sure that all the extractives were removed. The optimal extraction time has been determined in our previous experiments [10]. To remove alkali-soluble compounds, the extracted birch outer bark was treated for $1 \mathrm{~h}$ with $1 \% \mathrm{KOH}$-water solution (weight ratio $-1: 10$ ), intensively stirring under reflux. The obtained solution was filtered through a previously dried sintered glass crucible. After that, the same volume of fresh $1 \% \mathrm{KOH}$-water solution was added to the liquid fraction and the boiling process was continued for another $20 \mathrm{~min}$ under reflux. The solid residue was filtered, washed to $\mathrm{pH} 7$ and dried to a constant weight. The content of cellulose and acid-insoluble lignin in this solid material was determined by the Kürschner-Hoffer nitration method [11] and the TAPPI 222 standard method [12], accordingly. The liquid fraction was acidified to $\mathrm{pH} 4-5$ by concentrated nitric acid (65\% $\mathrm{v} / \mathrm{v})$. During the reaction, suberinic acids potassium salts were precipitated. After that these sediments were filtered, washed with deionized water and dried to the constant weight at $105 \pm 3{ }^{\circ} \mathrm{C}$. The content of ash in the untreated birch outer bark was determined according to the standard EN 14775 [13]. All the above-mentioned analyses were performed in triplicate.

\section{Obtaining of Suberinic Acids Containing}

\section{Binder}

For hydrolytic depolymerization in a basic water medium, the patented method was chosen [9]. Optimized suberin depolymerization conditions like alkali concentration in water, processing time and temperature were used from the previous studies of obtaining suberinic acids [14]. To obtain a suberinic acids containing binder, extracted outer birch bark was hydrolytically depolymerized in the solution of $3 \% \mathrm{KOH}$ (processing time $-1 \mathrm{~h}$, temperature -80 $90{ }^{\circ} \mathrm{C}$ ). Outer birch bark and $\mathrm{KOH}$ solution weight ratio was 1:10. The depolymerization process was carried out in a reactor, where the material was intensively stirred; the reactor was immersed in a water bath. At the end of the depolymerization process, the obtained suspension of the solution of suberinic acids potassium salts and other soluble compounds (potassium hydroxide, carbohydrates, etc.) and the insoluble residue (lignin, cellulose, etc.) was cooled down to a temperature of $15-20{ }^{\circ} \mathrm{C}$ and then acidified with $65 \%$ nitric acid solution to $\mathrm{pH} 2$. In the next step, the resulting mass was centrifuged for $1 \mathrm{~h}$ in the sedimentation centrifuge at $2000 \mathrm{~min}^{-1}$ rpm. The precipitate was further washed twice with distilled water and centrifuged until the solution reached $\mathrm{pH} 3$. At the end, the obtained paste could be easily mixed with wood sawdust. The suberinic acids containing binder was obtained in two replications.

\section{Determination of Binder's Acid Value}

A sample containing $0.12-0.15 \mathrm{~g}$ of dry suberinic acids was dissolved in $25 \mathrm{~mL}$ dimethyl sulfoxide for $20 \mathrm{~h}$ and then potentiometrically titrated with $0.1 \mathrm{M}$ $\mathrm{KOH}$ aqueous solution using a titration workstation (Titralab 980). The result was expressed as $\mathrm{mg}$ $\mathrm{KOH} / \mathrm{g}$ suberinic acids.

\section{E. Determination of Binder's Epoxy Groups}

The sample containing $0.12-0.15 \mathrm{~g}$ of dry suberinic acids was treated with $5 \mathrm{~mL}$ of non-aqueous $\mathrm{HCl}$ solution in dimethylsulfoxide (composition of the reagent $-100 \mathrm{~mL}$ dimethyl sulfoxide $+0.7 \mathrm{~g}$ hydroxylamine hydrochloride $+2 \mathrm{~mL}$ acetone) for 20 h. Then the excess of $\mathrm{HCl}$ was potentiometrically titrated with $0.1 \mathrm{M} \mathrm{KOH}$ aqueous solution using a titration workstation (Titralab 980). The blank sample, i.e. $5 \mathrm{~mL}$ of non-aqueous $\mathrm{HCl}$ solution in dimethylsulfoxide, was also titrated. The amount of epoxy groups was equivalent to the loss of hydrochloric acid estimated in the titration of the analysis and blank samples. The amount of the main 
suberinic epoxy acid (9,10-epoxy-18-hydroxyoctadecanoic acid) was calculated using a molecular weight of $313 \mathrm{~g} / \mathrm{mol}$. The result was expressed as \% from the o.d. suberinic acids containing binder.

\section{F. Particle Board's Preparation}

For the production of wood plate bio-composites, grey alder (Alnus incana (L.) Moench) sawdust with a fraction of $0.6-2.0 \mathrm{~mm}$ and a moisture content of $8.2 \pm 0.1 \%$ was used. The mixture of the binder (moisture content $78.9 \pm 0.2 \%$ ) prepared by alkalinewater hydrolytic depolymerization was mixed with a wood filler at the ratio of 20:80, 30:70 and 40:60. Then the produced raw material was dried in a drying chamber to a moisture content of $0.5-1.0 \%$. The dry mass (free-flowing material) was pressed on a laboratory press LAP-40 (Gotfried Joos Maschinefabrik $\mathrm{GmbH} \& \mathrm{Co}$ ) for $10 \mathrm{~min}$. The amount of the binder $\mathrm{X}_{1}=30 \pm 10 \%$ on o.d. mass, temperature $\mathrm{X}_{2}=180 \pm 20{ }^{\circ} \mathrm{C}$, and pressing pressure $\mathrm{X}_{3}=3 \pm 0.5 \mathrm{MPa}$ were chosen as the 3 main parameters for realizing the full factorial design (Table II), wherein the first value was the zero level for each parameter. Plates (dimensions of the plates $150 \times 150 \times 10-12 \mathrm{~mm}$ ), after pressing, were removed from the press without cooling. Pressed samples were conditioned in a climatic chamber at $55 \%$ humidity and a temperature of $20{ }^{\circ} \mathrm{C}$ for $48 \mathrm{~h}$. The quality of the obtained particle boards was characterized by density (EN 323) and bending strength (EN 310), which was determined on a testing machine Zwick/Roell Z010 (Ulm, Germany) [15], [16]. The test results are given as the average of the four parallel bending strength measurements.

\section{RESULTS AND DISCUSSION}

The chemical component analysis was performed in order to characterize industrial raw birch outer bark, and the results are summarized in Table I. Analysis series was started by extractive separation in a Soxhlet apparatus using ethanol as a solvent. Extracted birch outer bark was treated with $1 \% \mathrm{KOH}$ solution to determine alkali soluble substances. The main soluble substance of birch outer bark was suberinic acids, which represented hydrolytic depolymerization products of bio-polyester suberin. As shown by the results, with these two treatments, on average, $88.3 \%$ of the o.d. birch outer bark mass was separated. With the alkali treatment, not only suberinic acids were separated, but also other compounds (phenolic compounds, carbohydrates, etc.) with an amount of $14.9 \%$ from the o.d. birch outer bark mass. In contrast, insoluble cellulose, lignin and other components made only up to $9.6 \%$ from the o.d. bark mass.

In order to obtain the suberinic acids containing binder for production of bio-composites from wood particles, the method from a novel concept was used [9]. This technique is unique compared to similar methods of obtaining because the hydrolytically depolymerized salt solution of suberinic acids and the insoluble residual suspension are acidified before filtration [8]. In this way, not only acidified suberinic acids and other compounds are separated, but also the alkali insoluble solid residue.

To obtain the suberinic acids containing binder, $300.0 \mathrm{~g}$ (relative moisture content $5.2 \%$ ) of extracted birch outer bark was processed. At first, birch outer bark was hydrolytically depolymerized in alkaline conditions and then the obtained suspension, after cooling, was neutralized and acidified to $\mathrm{pH} 2$ to obtain the maximal amount of the binder in the chemical exchange reaction. The resulting suspension was centrifuged and washed twice to $\mathrm{pH} \mathrm{3}$, thus removing most of the residual acid, potassium nitrate salts and other soluble compounds. As a result, $1227.8 \pm 36.8 \mathrm{~g}$ of the suberinic acids containing paste was obtained with the dry matter content of $21.1 \pm 0.6 \%(259.1 \pm 0.5 \mathrm{~g})$. The yield was $91.1 \pm$ $0.2 \%$ from the o.d. extracted birch outer bark mass.

Table I

Content of Basic Components of Industrial Birch Outer Bark

\begin{tabular}{|c|c|c|}
\hline No & Components & $\begin{array}{l}\% \text { from the } \\
\text { o.d. raw } \\
\text { material }\end{array}$ \\
\hline 1. & Extractives of ethanol & $34.7 \pm 0.9$ \\
\hline \multirow[t]{3}{*}{2.} & $\begin{array}{l}\text { Substances soluble in } 1 \% \mathrm{KOH} \\
\text { solution* from which: }\end{array}$ & $53.6 \pm 1.1$ \\
\hline & Suberinic acids & $38.7 \pm 1.3$ \\
\hline & Other (condensed tannins, etc.) & 14.9 \\
\hline 3. & Cellulose** & $3.6 \pm 0.3$ \\
\hline 4. & Lignin** & $2.2 \pm 0.2$ \\
\hline 5. & Other $* *$ & 3.8 \\
\hline 6. & Ash & $2.1 \pm 0.1$ \\
\hline
\end{tabular}

The main adhesive component of the binder paste is represented by suberinic acids, which react at elevated temperature and as a result of the polycondensation reaction, generate a linear polymer structure. Later, a three-dimensional elastomer is formed, which is insoluble in organic solvents [17].

Taking into account the untreated birch outer bark chemical composition (Table I), the amount of the separated suberinic acids can reach, on average, up to $59.3 \%$ of the o.d. extracted bark mass. The content of suberinic acids in the obtained paste can reach, on average, up to $65.1 \%$ of the o.d. paste mass.

The suberinic acids containing binder was obtained in two parallel experiments to be further characterized with an acid number (carboxyl- groups) and the amount of epoxy groups.

After the depolymerization, the monomer composition of suberin mostly consists of fatty acids, $\omega$-hydroxyfatty acids, $\alpha$-, $\omega$-dicarboxylic acids, aliphatic alcohols and aromatic acids, depending on the plant material. $\omega$-hydroxyfatty acids are generally the most abundant group of suberin monomers in the outer bark of silver birch, and the main compounds in 
the suberinic acid mixture are epoxy and hydroxyl groups containing derivatives [18]. Thus, the hydroxyl and epoxy group content can be used for the characterization of the chemical composition repeatability of the used binder obtaining methodology. As demonstrated by the results, the obtained binder's acid number was $84.8 \pm 2.3 \mathrm{mg}$

Table II

Full Factorial Design for Plates obtained from Sawdust of Grey Alder using Suberinic Acids containing Binder

\begin{tabular}{|c|c|c|c|c|c|c|c|c|c|}
\hline Parameters & 1 & 2 & 3 & 4 & 5 & 6 & 7 & 8 & 9 \\
\hline $\mathbf{X}_{1}-\operatorname{Binder}(\%)$ & 20 & 20 & 20 & 20 & 40 & 40 & 40 & 40 & 30 \\
\hline $\mathrm{X}_{2}$ - Temperature $\left({ }^{\circ} \mathrm{C}\right)$ & 160 & 200 & 160 & 200 & 160 & 200 & 160 & 200 & 180 \\
\hline $\mathbf{X}_{3}$ - Pressure $(\mathrm{MPa})$ & 2.5 & 2.5 & 3.5 & 3.5 & 2.5 & 2.5 & 3.5 & 3.5 & 3.0 \\
\hline $\mathbf{Y}_{1}$ - Density* $\left(\mathrm{g} / \mathrm{cm}^{3}\right)$ & $\begin{array}{l}0.673 \pm \\
0.006\end{array}$ & $\begin{array}{l}0.682 \pm \\
0.007\end{array}$ & $\begin{array}{l}0.764 \pm \\
0.007\end{array}$ & $\begin{array}{l}0.856 \pm \\
0.005\end{array}$ & $\begin{array}{l}0.874 \pm \\
0.006\end{array}$ & $\begin{array}{l}0.916 \pm \\
0.003\end{array}$ & $\begin{array}{l}0.931 \pm \\
0.004\end{array}$ & $\begin{array}{l}1.056 \pm \\
0.006\end{array}$ & $\begin{array}{l}0.867 \pm \\
0.008\end{array}$ \\
\hline $\begin{array}{l}\mathbf{Y}_{2} \text { - Bending } \\
\text { strength** (MPa) }\end{array}$ & $\begin{array}{l}4.07 \pm \\
0.34\end{array}$ & $\begin{array}{l}5.27 \pm \\
0.41\end{array}$ & $\begin{array}{l}7.57 \pm \\
0.39\end{array}$ & $\begin{array}{l}12.50 \pm \\
0.29\end{array}$ & $\begin{array}{l}12.10 \pm \\
0.35\end{array}$ & $\begin{array}{l}13.30 \pm \\
0.86\end{array}$ & $\begin{array}{l}15.00 \pm \\
0.83\end{array}$ & $\begin{array}{l}17.10 \pm \\
0.67\end{array}$ & $\begin{array}{l}14.20 \pm \\
0.48\end{array}$ \\
\hline
\end{tabular}

Non load-bearing boards for use in humid conditions (P3) - Requirements for specified mechanical and swelling properties. * EN 312 requirements $-0.85 \mathrm{~g} / \mathrm{cm}^{3}$. ** EN 312 requirements $-15 \mathrm{MPa}$

$\mathrm{KOH} / \mathrm{g}$ and epoxy group content was $1.6 \pm 0.1 \%$. The low standard deviation values indicate that the resulting binder's chemical composition is uniform and therefore will affect the particle board properties insignificantly. Both binder samples, after their characterization, were used in the preparation of medium density particle boards.

The advantages of the binder preparation technology patented by the Latvian State Institute of Wood Chemistry are as follows: 1) the extracted bark raw material is processed completely and a potassium nitrate aqueous solution is formed as a by-product, which can be used as a plant fertilizer; 2) the raw material, product and processing methodology are environmentally friendly. According to the patented methodology, the product is washed only to $\mathrm{pH} 3$, and it results in less waste water compared to the case of similar extraction methods (more water is used for washing out to $\mathrm{pH} 7$ [8]).

To investigate the preliminary technological parameters of the green bio-composites obtained from depolymerized birch outer bark, the amount of the binder $\left(\mathrm{X}_{1}\right)$, pressing temperature $\left(\mathrm{X}_{2}\right)$ and pressure $\left(X_{3}\right)$ were chosen as 3 main parameters for realizing the full factorial design. Response variables for the preliminary parameters of the pressing of biocomposites were chosen by the density and bending strength of the obtained plate materials. The results obtained according to this method are shown in Table II.

$$
\mathrm{Y}_{1}=0.84+0.10 \mathrm{X}_{1}+0.03 \mathrm{X}_{2}+0.06 \mathrm{X}_{3}
$$

Equation (1), where the response variable is density, $Y_{1}\left(\mathrm{~g} / \mathrm{cm}^{3}\right)$, indicating that the higher densities are reached if the chosen parameters are above the zero level because all the coefficients are positive. More significant influence on the plate material density is demonstrated by the amount of the binder $(+0.10)$ and pressure $(+0.06)$, but the pressing temperature has less significance $(+0.03)$.

$$
\mathrm{Y}_{2}=10.86+3.51 \mathrm{X}_{1}+1.18 \mathrm{X}_{2}+2.18 \mathrm{X}_{3}
$$

Equation (2), where the response variable is bending strength, $\mathrm{Y}_{2}(\mathrm{MPa})$, indicating that the same tendency that the higher values are reached if the chosen parameters are above the zero level. More significant influence on the plate material bending strength is shown by the amount of the binder $(+3.51)$ and pressure $(+2.18)$, but the pressing temperature has less significance $(+1.18)$.

This means that the amount of the binder must be taken as high as possible to obtain a higher bending strength of the obtained plate materials. If we look at the properties of the plate samples obtained at the zero level parameters (experiment 9) and compare them with the calculated average values of the experimental plan in the respective equations, we can conclude that density is close to that obtained experimentally $\left(0.84\right.$ and $\left.0.86 \mathrm{~g} / \mathrm{cm}^{3}\right)$. In the case of bending strength, there is a significant difference in both values (10.86 and 14.2 MPa), which means that, for better bending strength, all parameters must be higher. The realization of such a task could increase the sample density. Therefore, it will be a great challenge to obtain bio-composites from depolymerized birch outer bark, which would conform to EN 312 requirements by choosing the appropriate filler or by changing the binder preparation conditions [19].

The obtained data show that the increase of the pressing temperature from 160 to $200{ }^{\circ} \mathrm{C}$ at a pressure of $3.5 \mathrm{MPa}$ and the amount of the binder $40 \%$ results in a minor growth of the boards' density (up to 1.0 $\mathrm{g} / \mathrm{cm}^{3}$ ) and bending strength (up to 17.1 MPa), but their density exceeds the standard limits specified in particle board standards. In this respect, for better results, our next initial parameter range will be as follows: 20 and $30 \%$ of the binder should be pressed at $200-220{ }^{\circ} \mathrm{C}$ and at lower pressure to obtain medium density (up to $0.85 \mathrm{~g} / \mathrm{cm}^{3}$ ) bio-composites with appropriate bending strength properties (below $15 \mathrm{MPa}$ ). A higher temperature was chosen based on the fact that it has less significance on the plate density (Equation 1). 
Environment. Technology. Resources, Rezekne, Latvia Proceedings of the $11^{\text {th }}$ International Scientific and Practical Conference. Volume III, 249-253

When pressing at high temperature, obviously, there occurs the formation of grid-type structures due to the generation of new chemical bonds between suberin and the wood filler; hence, the physicomechanical characteristics of bio-composites are improved without the potential emission of formaldehyde [20].

\section{CONCLUSIONS}

To obtain the suberinic acids containing binder for production of bio-composites from wood particles, a method from a novel concept was used. The content of suberinic acids in the obtained binder reached 65.1 $\%$ of the o.d. mass. The hydroxyl and epoxy group content was used for the characterization of the chemical composition.

More significant influence on the plate material density and bending strength was demonstrated by the amount of the binder and pressure, but the pressing temperature had less significance. Therefore, elevation of temperature was chosen for future investigations to obtain better mechanical properties of bio-composites.

Preliminary data showed that the increase of the pressing temperature from 160 to $200{ }^{\circ} \mathrm{C}$ at a pressure of $3.5 \mathrm{MPa}$ resulted in a minor growth of the boards' density (up to $1.0 \mathrm{~g} / \mathrm{cm}^{3}$ ) and bending strength (up to 17.1 MPa).

Our investigation has shown that it is possible to use one of the plywood production residues - outer birch bark - as a raw material for obtaining particleboards, which have good mechanical properties. The used methods are also environmentally friendly, realizable in practice and have a potential to be cost-effective. The obtained bio-composites do not have any harmful effects on human health.

\section{ACKNOWLEDGMENTS}

This study was supported by the European Regional Development Fund (ERDF) project No. 1.1.1.1/16/A/042.

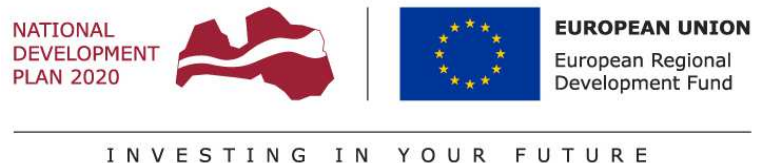

\section{REFERENCES}

[1] "Update on the formaldehyde release from wood-based panels // MDF Yearbook" Sept. 2008. [Online]. Available: http://chimarhellas.com/wp-
content/uploads/2008/07/FA 2008.pdf [Accessed Febr. 27, 2017].

[2] S. Wawzonek, "Formaldehyde depressed particle board," U. S. Patent 4457978A, July 3, 1984.

[3] S. Khosravi, F. Khabbaz, P. Nordqvist and M. Johansson, "Protein-based adhesives for particleboards," Ind. Crops Prod., vol. 32, pp. 275-283, 2010.

[4] N. S. Sulaiman, R. Hashim, M. H. M. Amini, O. Sulaiman and S. Hiziroglu, "Evaluation of the properties of particleboard made using oil palm starch modified with epichlorohydrin," BioResources, vol. 8, pp. 283-301, 2012.

[5] "Final Report Summary - FORESTSPECS, Wood Bark and Peat Based Bioactive Compounds, Speciality Chemicals, and Remediation Materials: from Innovations to Applications", [Online]. Available: http://cordis.europa.eu/result/rcn/149969 en.html [Accessed Febr. 27, 2017].

[6] P. A. Krasutsky, "Birch bark research and development," Natural Product Reports, vol. 23, pp. 919-942, 2006.

[7] A. N. Kislitsyn, "Outer birch bark extractives: isolation, composition, properties and application," Khimiya drevesiny (Wood Chemistry), vol. 3, pp. 3-28, 1994.

[8] I. G. Sudakova, N. V. Garyntseva and B. N. Kuznetsov, "Obtaining of wood plate materials using binders based on suberin of birch outer bark," Himija rastitel'nogo syr'ja (Chemistry of Plant Raw Material), vol. 3, pp. 65-68, 2011 (source is in Russian).

[9] J. Zandersons, J. Rižikovs, A. Pāže, A. Tardenaka and B. Spince, "Method for making formaldehyde-free particle boards," LV Patent 15031 (A), July 20, 2015.

[10] J. Rizhikovs, J. Zandersons, G. Dobele and A. Paze, "Isolation of triterpene-rich extracts from outer birch bark by hot water and alkaline pre-treatment or the appropriate choice of solvents," Ind. Crops Prod., vol. 76, pp. 209-214, 2015.

[11] A. V. Obolenskaya, Z. P. Elnitskaya and A. A. Leonovich, Laboratory Works in the Chemistry of Wood and Cellulose. Moscow: Ecologya, pp. 75-76, 1991 (source is in Russian).

[12] TAPPI 222 om-02:2006. Acid-insoluble lignin in wood and pulp.

[13] BS EN 1477:2009. Solid biofuels. Determination of ash content.

[14] I. G. Sudakova, B. N. Kuznetsov and N. V. Garyntseva, "A study of the isolation process of the suberinic substances from birch outer bark," Himija rastitel'nogo syr'ja (Chemistry of Plant Raw Material), vol. 1, pp. 41-44, 2008 (source is in Russian).

[15] BS EN 323:1993. Wood-based panels. Determination of density.

[16] BS EN 310:1993. Wood-based panels. Determination of modulus of elasticity in bending and of bending strength.

[17] V. A. Levandansky and S. A. Kuznetsova, Chemical Products of Wood Bark. Krasnoyarsk: Siberian State Technological University, 2012, pp. 146-162 (source is in Russian).

[18] J. Rižikovs, J. Zandresons, A. Pāže, A. Tardenaka and B. Spince, "Isolation of suberinic acids from extracted outer birch bark depending on the application purposes," Baltic Forestry, vol. 20, pp. 98-105, 2014.

[19] DIN EN 312:2010. Particleboards. Specifications.

[20] I. G. Sudakova, B. N. Kuznetsov, N. V. Garyntseva, N. I. Pavlenko and N. M. Ivanchenko, "Functional and thermal analysis of suberin isolated from birch bark," Journal of Siberian Federal University. Chemistry, vol. 4, pp. 355-362, 2008. 